\title{
POLÍTICAS DE INCLUSÃO: Avanços no campo da educação ou armadillhas do discurso neoliberal?
}

\author{
Terezinha Maria Schuchter \\ Janete Magalhães Carvalho ${ }^{(*)}$
}

É notável que, a partir dos fins da década de 1980 e início de 1990, a pobreza ganhou uma centralidade nas políticas públicas, ocorrendo a consolidação de um discurso a favor da "Educação para Todos", da educação inclusiva, de políticas de respeito à diversidade e da "tolerância", expresso em documentos de organismos internacionais - Banco Mundial (BM), Organizações da Nações Unidas (ONU), Programa das Nações Unidas para o Desenvolvimento (Pnud) e outros - bem como do Governo Federal brasileiro. Esse discurso pode ser observado no documento Superando o racismo na escola (BRASIL/MEC/Secadi, 2005, p. 9) no qual a educação é colocada como:

[...] um direito de todos, e o Brasil de hoje, graças aos esforços realizados nos últimos anos, já está muito próximo de ter todas as suas crianças na escola. Isso é essencial para a construção de um Brasil mais justo. Mas não é suficiente. É preciso, ainda, que a educação tenha qualidade, que sirva para abrir os espíritos, não para fechá-los, que respeite e promova o respeito às diferenças culturais, que ajude a fortalecer nos corações e mentes de todos os brasileiros o ideal da igualdade de oportunidades.

Vale ressaltar que esse discurso vai ao encontro das lutas de movimentos sociais - de negros, mulheres, indígenas, homossexuais, entre outros - em defesa de uma sociedade igualitária e da luta por garantia do direito ao acesso às políticas públicas, incluindo a educação gratuita, de qualidade e para todos.

Então poderíamos afirmar: as políticas inclusivas propostas pelo Governo Federal foram e estão sendo indicadas no sentido de atender a essas demandas da sociedade. Por que, então, um trabalho para discutir os sentidos dessas políticas? Muitos autores ${ }^{1}$ têm se dedicado a problematizar essas questões. Shiroma (2001, p. 4) aponta:

\footnotetext{
${ }^{(*)}$ Terezinha Maria Schuchter. Possui graduação em Licenciatura em Pedagogia pela Universidade Federal de Juiz de Fora (1990), mestrado em Educação pela Universidade Federal do Espírito Santo (1994) Doutorado em Educação pela Programa de Pós-graduação da Universidade Federal do Espírito Santo (2008). Professora Associada do Centro de Educação da Universidade Federal do Espírito Santo. E-mail: terezaschuchter@yahoo.com.br.

Janete Magalhães Carvalho. Pós-doutora em Currículo e Cotidiano Escolar pela Universidade do Estado do Rio de Janeiro e em Sociologia da Vida Cotidiana pelo Instituto de Ciências Sociais da Universidade de Lisboa. Doutora em Fundamentos da Educação pela Universidade Federal do Rio de Janeiro. Mestre em Educação pela Pontifícia Universidade Católica do Rio de Janeiro. Graduada em Pedagogia pela Universidade Federal do Espírito Santo. E-mail: janetemc@terra.com.br

${ }^{1}$ Lazzarato (2006, 2011), Veiga Neto e Lopes (2007), Shiroma (2001), Rech (2013) Lockman (2013), entre outros.
} 
A ideia de todos incluídos na comunidade global, sujeitos aos mesmos riscos, cria uma situação de igualdade simbólica que impõe a todos a responsabilidade e o compromisso moral de combater a pobreza e a exclusão social. Todos foram convocados, todos são parceiros nessa tarefa, empreitada mundial onde deveriam estar igualmente comprometidos e coesos. Que racionalidade preside este discurso? Que sutileza cirze esta colcha de conceitos? [...] Exclusão social é cara pelo fardo que impõe ao sistema de seguridade social e, também, pelos custos indiretos que surgem - por exemplo, a delinquência juvenil e a saúde precária que afeta os mais pobres da sociedade [...]. A ação de excluídos representa uma ameaça constante. Argumentos oficiais acabam expressando o que tentam ocultar: a atenção dada à chamada população vulnerável ou grupos de risco decorre da necessidade de controlá-los e do temor de instabilidades decorrentes de seus movimentos. No intuito de orientar o governo a conviver com incertezas e gerir imprevistos, autores influentes prescrevem a inclusão. Não há, contudo, consenso sobre como viabilizá-la.

Assim, a ideia da inclusão se concretiza no contexto atual porque "[...] uma das primeiras consequências da intervenção das políticas neoliberais no social [...] é o aumento da pobreza [...]. A nova pobreza é o produto de uma vontade política em uma sociedade capitalista [...]" (LAZZARATO, 2011, p. 50). Daí decorre a necessidade de diminuição dos efeitos negativos dessas políticas. O que poderia significar o aumento do número de pobres no planeta? Segundo Coraggio (1996, p. 22):

O processo de globalização inclui uma renovação nas instâncias políticas de âmbito mundial, como é o caso do sistema da ONU. Uma preocupação central daqueles que pensam em termos de uma ordem e um 'governo mundial" democráticos é como evitar que a globalização gere mais empobrecimento e exclusão, afetando as possibilidades de uma paz mundial que possa dar estabilidade e sustentação às tendências mais positivas em curso.

Aliado aos problemas decorrentes desse crescente aumento da pobreza, ainda podemos observar que as transformações econômicas e políticas impostas pelo neoliberalismo têm instituído novas práticas e formas de relações sociais que instituem um novo jeito de ser, de estar e de se relacionar na sociedade. São as transformações no campo cultural, garantidas pela mudança dos sentidos, dos discursos. A transformação do campo semântico não é apenas condição para o estabelecimento dessa hegemonia; ela é parte integral da transformação (SILVA, 1996, p. 82).

O fato é que essas transformações se apoiam em uma série de estratégias: deslocamento das causas, culpabilização das vítimas do sistema social, despolitização e naturalização do social, demonização do público, apagamento da memória e da história (SILVA, 1996). Dessa forma, instala-se entre nós a cultura do individualismo, da banalização da vida, a supervalorização do capital e da mercadoria, a fragmentação dos serviços e dos indivíduos, a naturalização e 
normalização da exclusão, entre outros. É o individualismo exacerbado em detrimento do coletivo. É o predomínio do econômico sobre todas as formas de vida e de organização social.

Assim, as lutas democráticas em defesa de alguns direitos sociais vão sendo capturadas e as "bandeiras" defendidas incorporadas ao discurso neoliberal. Depois de metamorfoseadas, instauram um processo de recriação de termos que passam a reproduzir e a redefinir o social, o político, o econômico, o educacional, o cultural e o ambiental. Nesse sentido, palavras como,educação pública e gratuita, qualidade, gestão democrática, autonomia, descentralização, direito social, cidadania e outras misturam-se a novas criações, como inclusão, globalização, nova ordem, flexibilidade, reestruturação produtiva, sujeito aprendente, capacidade de continuar aprendendo, entre outras.

No caso do Brasil, essas transformações agravaram o quadro da pobreza já existente e grande parte de sua população vive em condição de miséria, e muitos em miséria absoluta, completamente excluídos dos bens sociais, culturais e econômicos que são produzidos. As políticas que vem sendo implementadas e apregoadas como solução para a crise estão gerando um processo de degradação da vida, a legitimação da violência, da exclusão e a naturalização de todos esses processos. Trata-se de uma construção social baseada nas premissas do neoliberalismo.

Observamos a consolidação de políticas de cunho paliativo, as conhecidas políticas de reparação ou políticas afirmativas que têm caráter compensatório, de correção dos déficits, das faltas, das ausências que, de uma forma ou outra, apenas nutrem materialmente as existências - para não utilizar o termo erradicação ou combate à fome - expressões próprias do discurso governamental. Não são assim políticas de potencialização da vida, pois não descortinam outros possíveis. São políticas perversas, porque criam a falsa ideia da inclusão, são práticas excludentes incluem segregando.

É importante destacar que o discurso da necessidade da inclusão e da defesa da "Educação para Todos" decorre do reconhecimento de práticas que ainda segregam e excluem, ou seja, as lutas em torno da garantia do direito à educação podem não ter sido suficientemente capazes de garantir uma escola de/para/com todos, por isso ainda há que se questionar se a universalização do ensino fundamental - a garantia de acesso a todos - não está se efetivando por meio de uma "inclusão excludente". Isso porque essas políticas de inclusão podem supor que "todos" os sujeitos deverão ser incluídos para se enquadrarem dentro de uma forma/norma, gerando, assim, práticas homogeneizantes. É necessário, pois, “[...] examinar detida e cuidadosamente os elementos que estão em jogo, em termos de suas proveniências e emergências, articulações, superposições, especificidades e efeitos" (VEIGA NETO; LOPES, 2007, p. 950). 
O reconhecimento de que ainda há muitos excluídos do sistema educacional pode ser observado na Proposta de Plano Nacional de Implementação das Diretrizes Curriculares Nacionais da Educação das Relações Étnico-Raciais e para o Ensino de História e Cultura Afro-Brasileira e Africana (BRASIL, 2008, p. 5):

A educação básica ainda é profundamente marcada pela desigualdade no quesito da qualidade e é possível constatar que o direito de aprender ainda não está garantido para todas as nossas crianças, adolescentes, jovens e mesmo para os adultos que retornaram aos bancos escolares. Uma das mais importantes marcas dessa desigualdade está expressa no aspecto racial. Estudos realizados no campo das relações raciais e educação explicitam em suas séries históricas que a população afrodescendente está entre aquelas que mais enfrentam cotidianamente as diferentes facetas do preconceito, do racismo e da discriminação que marcam, nem sempre silenciosamente, a sociedade brasileira. $\mathrm{O}$ acesso às séries iniciais do Ensino Fundamental, praticamente universalizado no país, não se concretiza, para negros e negras, nas séries finais da educação básica. Há evidências de que processos discriminatórios operam nos sistemas de ensino, penalizando crianças, adolescentes, jovens e adultos negros, levando-os à evasão e ao fracasso, resultando no reduzido número de negros e negras que chegam ao ensino superior, cerca de $10 \%$ da população universitária do país.

Diante desse quadro, faz-se necessário um conjunto de "políticas de inclusão" visando a minimizar os efeitos perversos da exclusão social - expressão cunhada no contexto atual em substituição a pobreza e miséria.

\section{POLÍTICAS DE INCLUSÃO: Avanços no campo da educação ou armadilhas do discurso neoliberal? Alguns aportes dos documentos oficiais}

Educação para todos, educação inclusiva, políticas de inclusão ou simplesmente inclusão. Não há como negar que essas expressões vêm cunhando o debate educacional no período posterior à década de 1990. De forma geral, há quase uma unanimidade na sociedade quanto à aceitabilidade da necessidade de mecanismos de integração social das pessoas, tendo em vista as consequências geradas pelas políticas neoliberais em curso, que geraram o aumento da miséria - coincidentemente, no Brasil, também a partir desse período.

A palavra inclusão pode ser interpretada por diferentes formas, como movimento, processo, conceito, práticas, ideia, valor, política. De acordo com Menezes (2011, p. 29), “[...] a escola inclusiva passou a ser nomeada como uma questão de direitos humanos e sua concretização representaria um passo importante em direção à efetivação do conclamado direito universal à igualdade dos homens". Essa ideia é reiterada na Revista Inclusão (BRASIL/MEC/SEESP, 2005, p. 12): 
A educação inclusiva é antes de tudo uma questão de direitos humanos, já que defende que não se pode segregar a nenhuma pessoa como consequência de sua deficiência, de sua dificuldade de aprendizagem, do seu gênero ou mesmo se esta pertencer a uma minoria étnica (seria algo que iria contra os direitos humanos). [...] é uma atitude, representa um sistema de valores e de crenças, não uma ação simplesmente, mas sim um conjunto de ações.

Assim, o conceito de inclusão veio acompanhado da ideia de universalização do ensino fundamental, da obrigatoriedade da matrícula das pessoas portadoras de deficiência na escola regular, da obrigatoriedade do ensino da história e cultura africana e indígena nos currículos da educação básica, da instituição das modalidades da educação básica - quilombola, indígena, campo, educação de jovens e adultos, educação especial -, das políticas de reparação, da educação para todos, entre outras.

A ideia da inclusão como garantia de matrícula, obrigatoriedade, acesso, permanência e outros é destacada em vários documentos:

Um dos objetivos estratégicos apontados neste Documento [BRASIL, 2014] refere-se à garantia de matrícula, em qualquer época do ano, aos filhos e filhas dos ciganos. Esta é uma garantia universal que tanto o Ministério da Educação quanto os Sistemas de Ensino devem assegurar para que a inclusão seja, de fato, um componente real da educação brasileira. A garantia de escolarização para crianças, adolescentes, jovens, adultos e idosos ciganos nos munícipios do Brasil, bem como as condições de sua permanência na escola, é tarefa a que os órgãos públicos de ensino não podem abrir mão (BRASIL, 2014, p. 4).

Outro documento que trata de gênero e sexualidade na escola (BRASIL, 2009, p. 9) aponta que:

Durante todo o século XX e início do século XXI as lutas pela igualdade de gênero, étnico-racial e também pelo respeito à diversidade têm sido constantes. Todavia, o predomínio de atitudes e convenções sociais discriminatórias, em todas as sociedades, ainda é uma realidade tão persistente quanto naturalizada. O Brasil tem conquistado importantes resultados na ampliação do acesso e no exercício dos direitos, por parte de seus cidadãos. No entanto, há ainda imensos desafios a vencer, quer do ponto de vista objetivo, como a ampliação do acesso à educação básica e de nível médio, assim como do ponto de vista subjetivo, como o respeito e a valorização da diversidade. As discriminações de gênero, étnico-racial e por orientação sexual, como também a violência homofóbica, são produzidas e reproduzidas em todos os espaços da vida social brasileira. A escola, infelizmente, é um deles.

Não há como negar também que esse debate trouxe à tona importantes temas, como educação étnico-racial, gênero, sexualidades, direitos humanos e outros. Temas latentes desde muitos séculos passados, mas encobertos em nome de um dito e suposto padrão universal de normalidade que pressupunha um modelo de conhecimento, cultura e de existência humana - 
branco, europeu, cristão, heterossexual, sexista, masculino, machista, entre outros. Isso pode ser observado em um dos Cadernos Secadi (BRASIL/SECADI, 2007, p. 5):

Os temas abordados compreendem as questões da diversidade - étnico-raciais, de gênero e diversidade sexual, geracionais, regionais e culturais, bem como os direitos humanos e a educação ambiental. São analisados do ponto de vista da sustentabilidade e da inclusão social por meio de uma educação que seja efetivamente para todos, de qualidade e ao longo de toda a vida. Para isso, pressupõe-se que: i) a qualidade só é possível se houver equidade - isto é, se a escola atender a todos na medida em que cada um precisa; e ii) todas as pessoas têm direito de retornar à escola ao longo de sua vida, seja para complementar a Educação Básica, seja para alcançar níveis de escolaridade mais elevados ou melhorar sua formação profissional.

Assim, inclusão também aparece nos documentos com o sentido de políticas afirmativas, que são definidas como:

[...] políticas públicas (e privadas) voltadas à concretização do princípio constitucional da igualdade material e à neutralização dos efeitos da discriminação racial, de gênero, de idade, de origem nacional e de compleição física. Portanto, as ações afirmativas voltam-se para a neutralização daquilo que - de acordo com o status quo sociorracial - não se quer neutralizar (BRASIL/UNESCO, 2005a, p. 8).

O mesmo documento destaca que é necessário “[...] solidificar a inclusão da questão racial brasileira na agenda nacional, bem como defender ações afirmativas de acesso e permanência para negros nas universidades públicas" (BRASIL/UNESCO, 2005a, p. 25). Muitas são as formas de se conceber a inclusão, entretanto cabe-nos indagar: quais os sentidos atribuídos à palavra inclusão? Quais os significados das políticas inclusivas? Por que, contraditoriamente, o conceito de inclusão surge com a mesma força que os mecanismos de exclusão social? Por que gerar processos de exclusão de pessoas que depois deverão ser incluídas?

Lazzarato (2011) contribui para a compreensão dessas questões, ao problematizar as políticas de proteção social a partir do movimento dos trabalhadores do setor de espetáculos ocorrido na França, no período compreendido entre 2003 e 2007, empenhando-se em discutir os novos mecanismos de poder, de governabilidade e de assujeitamento dos indivíduos no contexto neoliberal. Segundo o autor, essas políticas estariam atreladas à ideia de governo das condutas.

O governo neoliberal da sociedade favorece a multiplicação das diferenças (de status, de rendimentos, de formação na gestão do mercado de trabalho, de pobreza, de desemprego, de precariedade, etc.), e ele converte essa multiplicação em modulação e em otimização das desigualdades. Ao mesmo tempo, e isso faz parte de um mesmo dispositivo, simultaneamente, micro e macropolítico do governo das condutas, ele favorece a reprodução de grandes divisões binárias (a divisão do capital e do trabalho, do emprego e do desemprego, da inclusão e da exclusão, etc.). (LAZZARATO, 2011, p. 13-14). 
Como afirmado, podemos inferir que o binômio inclusão/exclusão é uma construção - algo que se cria - e parte da lógica neoliberal, e pior, a inclusão é uma falsa realidade, porque efetivamente não inclui, não faz dos sujeitos pobres, nem dos negros, dos homossexuais, dos indígenas, das mulheres e de todos os que não se conformam ao padrão descrito anteriormente membros efetivos da sociedade. Estão e permanecerão à parte, excluídos. Sua integração fica no limite do tolerável. “Os excluídos são incluídos dentro de uma 'população' (o conjunto do mercado de trabalho) sobre a qual se exerce a ação governamental como gestão diferencial das desigualdades" (LAZZARATO, 2011, p. 25). Na verdade há um domínio da produção das desigualdades e da fabricação da miséria. A proteção contra os riscos e as políticas de ordem social são dispositivos que devem funcionar de forma mínima. O problema do governo não é mais a normalização da heterogeneidade, mas sim a gestão das diferenças (LAZZARATO, 2011). O autor afirma: “[...] o anormal, o excluído, o marginal não são mais o outro ou o fora, mas diferenças que precisam ser governadas em conjunção com outras” (p. 77). E destaca que "[...] as diferenças, as minorias, os comportamentos desviantes, por vezes antagonistas, serão controlados em 'bordas aceitáveis’ [ao invés de] lhes impor uma lei que diga não” (2011, p. 77).

A lógica neoliberal não quer nem a redução, nem a extinção das desigualdades pela simples razão que ela atua em cima dessas diferenças e governa a partir delas. Ela procura somente estabelecer um equilíbrio tolerável, um equilíbrio suportável para a sociedade entre normalidades diferentes: entre a normalidade da pobreza, da precariedade, e a normalidade da riqueza. Ela não se ocupa mais da 'pobreza relativa', das distâncias entre os diferentes rendimentos, e ela também não se ocupa mais de suas causas. Ela se interessa somente pela 'pobreza absoluta' que impede o indivíduo de disputar o jogo da concorrência. Ela deve apenas definir um limiar, um mínimo vital acima do qual o indivíduo pode se tornar uma 'empresa1, acima do qual as distâncias de rendimentos podem e devem ser importantes, e abaixo do qual ele cai fora do jogo social, do jogo da concorrência e no qual ele pode ser ajudado, mas de maneira pontual e não sistemática (LAZZARATO, 2011, p. 50$51)$.

O autor retoma o conceito de "monismo híbrido" (CERTEAU, 1995) e "pluralismo tolerado" (FOUCAULT, 2005) para descrever a otimização das desigualdades e a gestão diferencial das minorias como processo que "[...] transforma, reescreve, homogeneíza, totaliza conteúdos flexíveis em um esquadrinhamento duro" (LAZZARATO, 2011, p. 79). Para ele “[...] o esquadrinhamento não é aquele do confinamento disciplinar, mas sim o da circulação das diferenças cuja singularidade foi neutralizada no espaço aberto das sociedades de segurança” (p.79).

Inclusão e exclusão, normal e anormal não definem mais, como nas sociedades disciplinares, uma “grade divisão". Inclusão e exclusão são 'variáveis' da ação governamental que, aliás, têm a tendência a multiplicar os casos, as situações, os status entre esses dois limites. Portanto, o governo 
age, definitivamente, menos por divisão do que por modulação das divisões, das diferenças (LAZZARATO, 2011, p. 69).

Portanto, a sociedade de segurança se difere da sociedade disciplinar - que pressupõe uma conduta altamente uniformizante, segundo uma norma única e geral por meio dos processos de “normação". A sociedade de segurança não é uma "[...] sociedade na qual os mecanismos da normalização geral e da exclusão do não normalizável seriam requeridos” (FOUCAULT, 2008, p. 265), ou seja a normalização se opõe à “normação", pois conforme o autor “[...] é organizada sem o recurso a uma norma externa ao processo, mas apoiando-se sobre as próprias diferenças (anormalidades)" (p. 265). A operação de normalização "consistirá em fazer interagir essas diferentes atribuições de normalidade e procurar que as mais desfavoráveis se assemelhem às mais favoráveis” (FOUCAULT, 2008a, p. 83). Na sociedade de segurança, “[...] é o normal que é primeiro e a norma que se deduz dele, isto é, a norma não é exterior a seu campo de aplicação não só porque ela o produz, mas também porque ela se autoproduz ao produzi-lo" (LAZZARATO, 2011, p. 77). Para o autor, as formas de governo neoliberal nos fizeram sair da sociedade disciplinar, pois as políticas de governo das condutas se exercem por meio da gestão diferencial das anormalidades, das diferenças.

Como já afirmado, o único risco que os governos e os capitalistas temem é a ameaça à "paz mundial” ou "[...] os riscos da revolta, da politização, da anulação ou mesmo da simples redução de seus 'privilégios', entre eles, a própria propriedade privada, que eles consideram como o mais 'humano' de todos os direitos” (LAZZARATO, 2011, p. 52). Daí a necessidade das políticas de inclusão. Com essas políticas, os sujeitos "anormais", diferentes, improdutivos - que fogem ao padrão descrito acima - são aproximados da sociedade e, a partir daí, pode-se desenvolver uma série de estudos e saberes sobres eles, sua capacidade de produção, suas regularidades e irregularidades, de modo a governar a todos e a cada um (LOCKMAN, 2013). Assim:

[...] a tríade aproximar, conhecer e governar torna-se importante na medida em que possibilita pensar a inclusão como uma estratégia biopolítica que gerencia os riscos causados, nesse caso, pela anormalidade. Explicando melhor: a inclusão é o processo que irá possibilitar a aproximação desses sujeitos - anormais - na sociedade. Somente mediante essa aproximação - é que se torna possível produzir saberes sobre eles e, em consequência, desenvolver estratégias que controlem e regulem suas formas de ser, enfim, que orientam, suas condutas. Conduzir suas condutas é necessário na medida em que esses sujeitos são entendidos como uma ameaça à ordem moderna, como uma periculosidade social. (p. 130).

Rech (2013) faz alguns apontamentos sobre os discursos, práticas e políticas de inclusão desde o começo da década de 1990 e nos mostra que, no início, a lógica do movimento da inclusão 
se centrava na questão da obrigatoriedade escolar, do acesso e permanência dos estudantes na escola. Tratava-se de integrar e o sucesso da permanência tornava-se responsabilidade do sujeito. Colocava-se uma série de engrenagens em funcionamento, que produzia um movimento circular em que a maioria não atingia o objetivo estabelecido: completar o ciclo de escolaridade e chegar ao mercado de trabalho.

Isso pode ser observado no Relatório Educação para Todos no Brasil - 2000-2015, que aponta que:

Quando da Conferência Mundial de Educação para Todos, em Jomtien (1990), o Brasil tinha diante de si inúmeros desafios - o principal deles, sem desmerecer os demais, estava associado à expansão do acesso ao ensino fundamental. As reformas dos anos 90 do século XX estão associadas a esta meta [...]. Os objetivos então definidos coincidiram com a definição de novas prioridades na política educacional - assegurado o acesso ao ensino fundamental, foi possível cuidar melhor da permanência, expandindo etapas e modalidades não contempladas com igual ênfase na década anterior. O período mais recente, ainda em curso, corresponde a um momento de abertura de oportunidades a segmentos até então excluídos da atenção e do foco das políticas públicas. Os anos 2000 configuram-se, assim, como aqueles da inclusão. Este processo tem muitas dimensões, algumas das quais contempladas neste Informe, mas extrapolam o campo da educação escolar. Para a próxima Conferência Mundial de Educação para Todos, a se realizar na Coreia, em 2015, o Brasil leva um balanço do percurso realizado desde Dakar na expectativa de confrontar as metas já estabelecidas no horizonte de seu Plano Nacional de Educação e dos objetivos comuns aos países a serem estabelecidos nessa oportunidade. É certo que ainda há muito por fazer em termos de expansão do acesso, sobretudo em relação à Educação Infantil, ao Ensino Médio e à Educação Superior, assim como de segmentos antes excluídos, ora contemplados pelas políticas de inclusão e diversidade. $\mathrm{O}$ desafio posto para os anos que se aproximam é o da universalização. $\mathrm{O}$ foco da política educacional deverá buscar o equilíbrio entre metas quantitativas e qualitativas, caminho desafiante, sobretudo ao se considerar o quanto o País ainda tem por fazer em matéria de redução das desigualdades. A qualidade da educação implica cuidar (mais e melhor). (BRASIL, 2014a, p.122, grifos nossos).

Nas primeiras décadas do século XXI, podemos observar uma mudança nas lógicas das políticas de inclusão que passam a funcionar a partir da ideia de fluxo e habilidade. Segundo Rech (2013, p. 36):

\footnotetext{
A tentativa de pensarmos a noção de fluxo conjuntamente com a noção de habilidade pode ser justificada se olharmos para algumas palavras-chave do nosso cotidiano atual. Expressões como autonomia, adaptabilidade, criatividade, competências, flexibilidade, liderança e talento, sempre combinadas com o desejo de inovação, estão presentes não apenas na atmosfera empresarial, mas também em todo o campo educacional.
} 
A escola, como afirmado no início deste trabalho - que sempre teve uma forte relação com a formação para o mercado de trabalho - retoma sua função social histórica - embora com ênfase no indivíduo - e passa a alimentar a lógica neoliberal ao repassar aos sujeitos incluídos a responsabilidade pela:

[...] busca de alternativas que permitam sua inserção na lógica [de produção [e] de consumo e, com isso, objetiva o fortalecimento do mercado através do estímulo à competição. Nessa lógica competitiva, cabe à escola muito mais do que ensinar: cabe, agora, aprender a empregar. $\mathrm{O}$ aluno considerado incluído passa a receber novos rótulos, nesse caso rótulos que o obrigam a produzir, a ser útil e fazer a sua parte pelo crescimento da sociedade onde vive (RECH, 2013, p. 38).

A ideia de fluxo está, pois, ligada aos processos de inclusão, fazer entrar na escola aqueles, até então, foram considerados "pesos" aos governos que deveriam assisti-los, para que se tornem indivíduos com potencialidades adquiridas no processo educativo. Isso faz da escola "[...] um novo espaço de adaptação, de transitoriedade e de estímulo ao desejo" (RECH, 2013, p. 39).

Estamos na era da 'educação para a vida toda', que compreende moldar - já na figura do aluno personalidades sensíveis, flexíveis e polivalentes para que posteriormente, se tenham profissionais com as mesmas características: sujeitos que saibam, acima de tudo, governar a si mesmos, avaliar suas posturas e regular suas condutas em um espaço e tempo dinâmicos [...] temos a necessidade de abarcar e proteger uma massa global que precisa ser conduzida, primeiramente, pela escola para que possa conquistar novos espaços sociais, e, assim ser (re)conduzida de outras formas. Com as estratégias bioplíticas, obtendo-se, desse modo, a relação direta da política com a vida, é possível impetrar formas eficientes para se conhecer a fundo a massa que se quer conduzir. (p. 39-40).

A Revista Inclusão deixa clara essa concepção ao apontar que inclusão:

[...] é o meio mais efetivo de combater as atitudes discriminatórias, criando comunidades acolhedoras, construindo uma sociedade inclusiva e alcançando a educação para todos, além disso proporciona uma educação eficaz para a maioria das crianças, melhora a eficácia e, por fim, a relação custo-efetividade de todo o sistema educativo [...]. É uma atitude, um sistema de valores, de crenças, não uma ação nem um conjunto de ações. Centra-se, pois, em como apoiar as qualidades, e, as necessidades de cada aluno e de todos os alunos na comunidade escolar, para que se sintam bemvindos e seguros e alcancem êxitos [...]. Como se depreende dessas definições, a educação inclusiva centra-se em como apoiar as qualidades e as necessidades de cada um e de todos os alunos na comunidade escolar, para que se sintam bem-vindos e seguros e alcancem o êxito. (BRASIL/MEC/SEESP, 2005, p. 12).

Ainda esclarece que:

A educação inclusiva é um meio privilegiado para alcançar a inclusão social, algo que não deve ser alheio aos governos e estes devem dedicar os recursos econômicos necessários para estabelecê-la. Mais ainda, a inclusão não se refere somente ao terreno educativo, mas o verdadeiro significado de 
ser incluído. Está implícita, na inclusão social, a participação no mercado de trabalho competitivo (BRASIL/MEC/SEESP, 2005, p.14).

Diante do exposto, cabe-nos continuar com nossas interrogações. As políticas de inclusão estão dadas, estão postas. O que temos feito nós dessas políticas? Temos apenas permitido, na escola, o movimento circular de fluxo e garantia de pequenas habilidades aos incluídos - como é a proposta neoliberal - ou temos problematizado essas políticas e seus objetivos? Nossas problematizações têm possibilitado novos sentidos, movimentos e fluxos? Os incluídos têm tido lugar central no trabalho escolar?

\section{CONSIDERAÇÕES FINAIS}

É indiscutível a importância de se colocar em pauta temas até então negligenciados pela sociedade e pelas escolas. Questões étnico-raciais, sexualidade, gênero, direitos de grupos excluídos social, cultural, política e economicamente, enfim, questões que envolvem grupos humanos com especificidades, culturas, experiências, histórias, ou seja, formas de existência e vidas infames (FOUCAULT, 2003; LOBO, 2015). Essas vidas precisam ser trazidas à luz, porque ao longo da história se constituíram:

[...] sem notoriedade, obscuras como milhões de outras que desaparecem e desaparecerão no tempo sem deixar rastro - nenhuma nota de fama, nenhum feito de glória, nenhuma marca de nascimento, apenas o infortúnio de vidas cinzentas para a história e que se desvanecem nos registros porque ninguém as considera relevantes para serem trazidas à luz. Nunca tiveram importância nos acontecimentos históricos, nunca nenhuma transformação perpetrou-se por sua colaboração direta. Apenas algumas vidas em meio a uma multidão de outras, igualmente infelizes, sem nenhum valor (LOBO, 2015, p. 13).

Essas existências, quando dignas de registro, foram no sentido da ordenação da diferença, da fixação da norma ou da produção de conhecimento no intuito de controlá-las, pois nada mais foram ou são do que seres desviantes, problemáticos, deficitários. Classificação, hierarquização, enquadramento, eis o que predominou. Agora mesmo, diante do efusivo discurso da inclusão, somos chamados a nos interrogar: há algo diferente nas políticas atuais ou estamos vivenciando a reprodução das históricas práticas segregadoras e autoritárias?

Diante do exposto neste trabalho, tendemos a afirmar que as políticas atuais não têm o objetivo de levar os diferentes, os pobres, os deficientes ao isolamento, aos tribunais ou à morte, mas continuam produzindo formas de segregação de diferentes espécies, porque agora não se trata apenas da diferença, mas da desigualdade social, manipulada pelos ideais da igualdade universal (LOBO, 2015). 
A ideia de que a educação é direito de todos e para todos os indivíduos, ou seja, um direito universal e individual vem sendo colocada como capaz de dirimir as desigualdades, mas, na verdade, trata-se de uma igualdade formal, ancorada nos princípios liberais, que contrariam os movimentos de defesa e reconhecimento das diferenças. "Não são apenas os diferentes que são privados de suas vidas para se enquadrarem na mesmidade universal, todos perdem o seu direito à diferença ao serem integrados na promessa de todos como um” (MACEDO, 2015, p. 897 - 898). Outra hipótese - que vincula essa ideia às políticas neoliberais - reconhecida nas próprias publicações do Governo Federal, como o documento Acesso e permanência da população negra no ensino superior (BRASIL/UNESCO, 2007, p. 31), é a de que os que mais precisam ser beneficiados pela ideia de educação para todos podem não ser contemplados:

Até o presente momento [...] os recursos gastos em políticas públicas nomeadamente 'universais' vêm sendo apropriados (e concentrados) de uma forma etno-racialmente determinada e, para piorar, a adoção de medidas 'focalizadas', feita segundo a lógica neoliberal e articulada com políticas econômicas monetaristas ortodoxas, deixa de fora os que sempre estiveram de fora.

O documento aponta ainda que:

[...] os princípios de universalidade e do direito não são garantidos, as chamadas políticas de inclusão correm um sério risco de se transformarem em políticas pobres para pobres, cuja estratégia de focalização deixa de fora boa parte dos próprios pobres que ela pretende cobrir, bem como aqueles setores historicamente já discriminados, [...] mulheres e negros (PAIM, 2003, p. 31).

Macedo (2015, p. 897) contribui com o debate mostrando que:

[...] o universalismo repousa e sempre repousará, senão em exclusões, pelo menos na indiferença em relação a certas particularidades que ameaçam à abstração. O triunfo do indivíduo universal como representação de todos é produzido pelo esquecimento do sujeito concreto que ameaça a pureza da representação - negros, mulheres, pobres, homossexuais, judeus, nordestinos, a depender do momento histórico [...]. Tais políticas estão longe do reconhecimento da diferença, elas atuam definindo um país 'culturalmente diverso, mas politicamente homogêneo' [...]. A diferença cultural é aceita no âmbito privado, mas a representação política, o cidadão, segue sendo pensado em termos abstratos.

Assim primeiramente observamos que prevalece, no discurso governamental, uma ideia de inclusão universalista, de uma educação para todos. Trata-se de incluir os diferentes numa escola homogênea, modelar para que sejam enquadrados em modelos determinados e, se isso não ocorre, o problema é do indivíduo "desviante”, incapaz. Em segundo lugar, a inclusão é um imperativo moral mundialmente defendido como direito humano (MENEZES, 2011). Sendo garantida, os incluídos passam a ser responsabilizados pela "benesse recebida", pelo uso e apropriação do que pode resultar dessa política. Caso não consigam usufruir satisfatoriamente do que lhe está sendo oferecido - de imperativo moral passa-se à responsabilização moral. É a atribuição de um peso que só cabe ao 
indivíduo carregar. A sociedade é justa, as oportunidades foram garantidas, então o problema está nos indivíduos, ou seja, é a culpabilização das vítimas pelo seu próprio fracasso. Entretanto, podemos afirmar que é necessário reconhecer “[...] os fatores que vêm determinando a reprodução das desigualdades e tomar a focalização como um instrumento de correção desses desvios históricos e não como alternativa de política social” (CARNEIRO, 2003, apud BRASIL/UNESCO, 2007, p. 31).

Como já foi dito, trata-se, na verdade, de uma forma de gestão diferencial dos modos de vida, tendo em vista atender à única preocupação dos governos neoliberais, que é a pobreza absoluta que impede os indivíduos de disputar o jogo da concorrência e de produzir indefinidamente de modo a garantir o crescimento econômico, para uma determinada parcela da sociedade. “A concepção de indivíduo como ‘empresário de si mesmo' é o objetivo do capital como máquina de assujeitamento" (LAZZARATO, 2011, p. 43). Isso parece discurso de décadas passadas, mas a “[...] hipomodernidade e neoarcaísmo não são processos contraditórios, mas sim, duas faces complementares de uma mesma moeda do governo de nossas sociedades” [...] (p. 43). Ainda de acordo com Lazzarato (2011, p. 73), citando Guatari (1987), todo movimento capitalista ininterrupto não pode acabar "em outra coisa que não em dobras sobre ele mesmo, em reterritorializações de ordem nacionalista, classista, corporativista, racista, paternalista".

A centralidade das políticas de inclusão, portanto, não são os pobres, negros, mulheres e outros, no que tange às suas vidas e existências precárias, mas a transformação dessas vidas em vidas produtivas e controláveis. Assim sendo, concluímos que a perspectiva dominante no discurso governamental sobre inclusão aproxima-se de uma retórica discursiva (sem correspondência concreta com o diferente), despotencializadora de uma mudança efetiva na forma de conceber a diferença e a inclusão no currículo prescrito e vivido na escola. Trata-se de tratar a diferença a partir ideia da tolerância, por meio da ilusão do tratamento igualitário, como se todos "fossem iguais", ou a diferença considerada a partir de aspectos deficitários e problemáticos. Isso é o que sedimenta as políticas compensatórias, afirmativas, de reparação, de tolerância e os processos de aculturação. 


\section{REFERÊNCIAS}

BRASIL. Ações afirmativas e combate ao racismo nas Américas. A. S. Sales (Org.). Brasília: MEC/Unesco, 2005. (Col. Educação para Todos, 5).

Superando o racismo na escola. 2. ed. Kabengele Munanga. (Ed. e Org.). Brasília: MEC/SECAD, $2005 a$.

. Inclusão: revista da educação especial. Brasília: Secretaria de Educação Especial, 2005.

. Educação do campo: diferenças mudando paradigmas. Henriques et al. (Org.). Brasília: Secadi, 2007.

. Acesso e permanência da população negra no ensino superior. M. A Lopes; M. L. Braga (Orgs.). Brasília: MEC/SECAD/Unesco, 2007. 358 p. (Col. Educação para Todos, v. 30).

Proposta de Plano Nacional de Implementação das Diretrizes Curriculares Nacionais da Educação das Relações Étnico-Raciais e para o Ensino de História e Cultura Afro-Brasileira e Africana - Lei 10.639/2003. Brasília: Secadi, 2008.

Ciganos: documento orientador para os sistemas de ensino. Brasília: Secadi, 2014.

Relatório educação para todos no Brasil 2000-2015. Brasília: MEC, 2014a.

CARNEIRO, S. Focalização x universalização. In: BRASIL/UNESCO. Acesso e permanência da população negra no ensino superior. Brasília: MEC/Secad/Unesco, 2007. 358 p. (Col. Educação para Todos, 30).

CERTEAU, M. A cultura no plural. Campinas: Papirus, 1995.

CORAGGIO, J.L. Desenvolvimento humano e educação: o papel das ONGs latino-americanas na iniciativa da educação para todos. São Paulo: Cortez, 1996.

FOUCAULT, M. A vida dos homens infames. FOUCAULT, M. In: Estratégia, poder-saber. Ditos e escritos IV. Rio de Janeiro: Forense Universitária, 2003.

. Arqueologia das ciências e história dos sistemas de pensamentos. Ditos e Escritos II. Organização e seleção de textos Manuel Barros da Motta. Trad.: Elisa Monteiro. 2. ed. Rio de Janeiro: Forense Universitária, 2005.

. Nascimento da biopolítica. São Paulo: Martins Fontes, 2008.

Segurança, território e população. São Paulo: Martins Fontes, 2008a.

LAZZARATO, M. As revoluções do capitalismo. Rio de Janeiro: Civilização Brasileira, 2006.

O governo das desigualdades: crítica da insegurança neoliberal. São Paulo: EdUFSCar, 2011.

LOBO, L. F. Os infames da história: pobres, escravos e deficientes no Brasil. 2. ed. Rio de Janeiro: Lamparina, 2015.

LOCKMAN, K. medicina e inclusão escolar: estratégias biopolíticas de gerenciamento do risco. In: FABRIS, E. T.; KLEIN, R. R. (Org.). Inclusão e biopolítica. Belo Horizonte: Autêntica Editora, 2013. (Coleção Estudos Foucaultianos).

MACEDO, E. Base nacional comum para currículos: direitos de aprendizagem e desenvolvimento para quem? Educação e Sociedade, Campinas, v. 36, n. 133, p. 891-908, out./dez. 2015.

MENEZES, E. C. P. A maquinaria escolar na produção de subjetividade para uma sociedade inclusiva. 2011. Tese (Doutorado em Educação) - Programa de Pós-Graduação, Universidade do Vale do Rio dos Sinos, São Leopoldo, 2011.

PAIM. P. Reformas: raça, gênero e políticas de inclusão social. Seminário realizado na Comissão de Constituição, Justiça e Cidadania do Senado Federal. Brasília: Senado Federal, 13-5-2003, p. 103-105.

RECH, T. L. A inclusão educacional como estratégia biopolítica. In: FABRIS, E. T.; KLEIN, R. R. (Org.). Inclusão e biopolítica. Belo Horizonte: Autêntica Editora, 2013. (Coleção Estudo Foucaultianos).

SILVA, T. T. O projeto educacional da "nova" direita e a qualidade total. Universidade e Sociedade. Brasília: Andes, ano VI, n. 10, jan. 1996, p. 82-89.

VEIGA NETO, A.; LOPES, M. C. Inclusão e governabilidade. Educação e Sociedade. Campinas, v. 28, n. 100, p. $947-$ 963, out. 2007.

SHIROMA, E. O. A outra face da inclusão. Teias: Rio de Janeiro: ano 2, n. 3, jan./jun., 2001. 


\section{RESUMO}

Objetiva o artigo discutir os sentidos atribuídos às políticas de inclusão nos documentos da Secretaria de Educação Continuada, Alfabetização, Diversidade e Inclusão (Secadi). Utiliza, como abordagem metodológica, a pesquisa documental e bibliográfica e a análise do discurso, tecendo reflexões acerca dos fundamentos do conceito de inclusão e das finalidades das políticas inclusivas no contexto atual. Diante do fato da educação inclusiva estar se constituindo como uma política nacional, cabe-nos perguntar: quais os sentidos das políticas de inclusão no discurso governamental? Seriam essas políticas efetivamente inclusivas ou uma forma de gestão diferencial dos modos de vida para o controle da população? Quais seriam as implicações desse discurso para o campo do currículo escolar.

Palavras-chave: Política. Inclusão. Direito.

\section{INCLUSION POLITICS: ADVANCES IN THE FIELD OF EDUCATION OR TRAPS OF THE NEOLIBERAL DISCOURSE?}

\section{ABSTRACT}

This article aims to discuss the meanings attributed to the inclusion policies in the documents of the Secretariat of Continued Education, Literacy, Diversity and Inclusion or, in its original name, Secretaria de Educação Continuada, Alfabetização, Diversidade e Inclusão (Secadi). It uses, as a methodological approach, documental and bibliographic research and the analysis of speech, promoting reflections about theoretical foundations to the concept of inclusion and the purposes of inclusive policies in the current context. Ahead of the fact that inclusive education is forming itself as a national policy, we have to ask: what are the meanings of inclusion policies in the governmental speech? Are those policies effectively inclusive or just different management of lifestyles in order to control the population? What are the implications of this speech to the field of school curricula?

Keywords: Politics. Inclusion. Entitlements.

Submetido em: Set. 2016

Aprovado em: Jan. 2017 